\title{
Matéria Evaluation of zinc oxide nanoparticles influence on hydrophilic polymer matrix systems
}

\author{
Jacqueline Silva Cardoso Lunz ${ }^{1}$, Paulo Sérgio Rangel Cruz da Silva ${ }^{1}$, \\ Maria Inês Bruno Tavares ${ }^{1}$
}

\begin{abstract}
${ }^{1}$ Universidade Federal do Rio de Janeiro, Instituto de Macromoléculas Professora Eloisa Mano, Brasil, Avenida Horácio Macedo, 2030, Bloco J, Centro de Tecnologia, Ilha do Fundão, CEP: 21941-598, Rio de Janeiro, Rio de Janeiro, Brazil. e-mail: mibt@ima.ufrj.br
\end{abstract}

\begin{abstract}
Hydrophilic polymer matrix systems (HPMSs) are a highly relevant tool for drugs delivery whose bioavailability is impaired by low hydrosolubility. Besides this, when associated with nanoparticles these systems can provide better control over release profile of the active drug, maintaining the posology. Since polyvinylpyrrolidone (PVP) and zinc oxide ( $\mathrm{ZnO})$ are safe materials for use in the human body, we studied the effects of $\mathrm{ZnO}$ nanoparticle ratios on the characteristics of PVP matrix. For that purpose, nanocomposites were prepared by solution casting method and characterized by X-ray Fluorescence (XRF), Fourier Transform Infrared (FTIR), Thermal Gravimetric Analyses (TGA), Differential Scanning Calorimetry (DSC), X-ray Diffraction (XDR) and Low-field Nuclear Magnetic Resonance (LF-NMR) technique, using relaxometry. We also analyzed the effects of the system on two broad-spectrum antimicrobial drugs. The characterization results of the new materials indicate good interaction of the nanoparticles with the polymer, and this fact suggests that these new materials may have a retarding effect on drug release. The results also showed no disruptive interaction of the matrix system important to the action of the antimicrobials.
\end{abstract}

Keywords: Polymer, Nanotechnology, Drug delivery, ZnO.

\section{INTRODUCTION}

Drugs administered orally in solid form can be classified according to the release mechanism of the active ingredient in the body. By tailoring for the pharmaceutical formulation, the release can be conventional or modified, in which the availability of the drug is delayed or sustained. In this case, the systems are considered to be time-dependent, able to maintain blood concentrations at therapeutic concentrations for longer periods [1], [2]

The use of polymers to modulate drug release in specific situations is related directly to the intrinsic properties of the polymer, such as the ability to form microporous or semipermeable structures, swelling in water and complexation with drugs. These characteristics can give rise to systems with various morphologies for modulating drug release, including hydrophilic polymer matrix systems [3].

Although the polymers already have be shown to have wide pharmacotechnical applications, recent research has indicated that the efficiency in controlling drug release can be enhanced by the incorporation of nanoparticles in the polymer matrix, forming polymer nanocomposites [4]. These nanocomposites can act as efficient complexes barrier that inhibit the diffusion of the drug permeating these materials layer by layers dispersed and distributed in the matrix, regulating the permeation to the body [5], [6];. Therefore, it is worthwhile learning the possible interferences or interactions of nanostructures with the system as a whole.

In this present study was observed the influence of zinc oxide $(\mathrm{ZnO})$ nanoparticles on the structure of a hydrophilic matrix composed of polyvinylpyrrolidone (PVP), which is a polymer widely used in pharmaceutical applications. To assess the microstructural alterations of the proposed system on drug release, two antimicrobials were tested: trimethoprim and sulfamethoxazole, bacteriostatic agents normally employed in association.

Hydrophilic Polymer Matrix Systems (HPMSs) promote drug release due to the swelling of the poly- 
mer by the action of the water present in the fluids of the gastrointestinal tract, and then diffusion of the drug and/or erosion of the matrix, may occur. These parameters vary according to the physico-chemical properties of the polymer nanocomposites, after drug incorporation, as well as the kinetics and release control mechanisms. The penetration of water through the matrix promotes transition of the polymer from a glassy state to swollen state as the intermolecular interactions between chains change. This reduces the polymer-polymer attraction forces, leading to more freedom conformational, allowing the drug to diffuse gradually making a tortoise way due to the presence of layers in the system [3], [7]-[10]. The swelling of hydrophilic matrixes due to the relaxation of the polymer chains when in contact with an aqueous medium is described as the formation of "fronts", which delineate the different phases of the matrix [11].

Polyvinylpyrrolidone is a polymer commonly used in pharmaceutical applications due to its actions for agglutination, disintegration, and especially PVP promotes of dissolution of drugs that have low water solubility. This last effect is attributed to the ability to form a porous polymer matrix structure when in an aqueous medium. This leads to a considerable increase in the drug's contact surface with the dissolution medium [12].

PVP is a white or light yellow powder soluble in water and organic solvents. It is biocompatible and does not form crystalline structures (amorphous nature). Its molar mass is measured for commercial purposes in function of the Fikentscher value $(\mathrm{K})$, derived from the viscosity of the solution [13]. The fact that the $\mathrm{K}$ value has a well-established relation with the expected molar mass of this polymer makes knowledge of this parameter relevant in determining the application of the material. Molar mass above 50,000 g/mol reduce the hydrosolubility of the PVP, increasing its viscosity. This justifies its use to modulate the release of drugs.

Polymers with similar characteristics and properties have been described regarding their bioadhesive properties, i.e., mucoadhesion capability. The bioadhesion phenomenon is not fully understood, but it is believed to involve three important kinetic steps: adsorption, spreading of the bioadhesive polymer material over the mucosa, and interpenetration of the chains of the polymer and mucosa. Therefore, the increase in the contact surface in function of high molar mass, as well as the ability to form hydrogen bonds and flexibility of the polymer chains, enables the interpenetration of the material by the main protein of mucus, allowing establishing the physical and chemical interactions[12].

The chemical and physical properties make PVP's use in nanocomposites attractive. This is a strategy employed in various pharmaceutical formulations, in which a hybrid composition is obtained from structures with a least one dimension having nanometric scale, well dispersed and distributed in a polymer matrix, to improve or totally alter the pharmacotechnical parameters. This allows designing the release profile, as well as directing the drug to the target organ or tissue, reducing the posology and/or toxicity of some drugs [9], [13]-[16].

Thus, according to the exposed the present work was based on developing nanocomposites of $\mathrm{PVP} / \mathrm{ZnO}$ to be used as an agent to drug delivery systems, for two drugs trimethoprim and sulfamethoxazole. The novelty of this work is the obtained systems and also the characterization of those, mainly employing nuclear magnetic resonance relaxometry that allowed understanding the behavior of the new materials.

\section{MATERIAIS E MÉTODOS}

\subsection{MATERIALS}

In this work was used poly(vinylpyrrolidone) (PVP K30) from Sigma-Aldrich Chemistry as a matrix, zinc oxide $(\mathrm{ZnO}<100 \mathrm{~nm})$ from Sigma-Aldrich Chemistry as nanoparticle and sulfamethoxazole and trimethoprim, both from Virchow Laboratories, as drugs.

\subsection{PREPARATION OF THE SAMPLES}

The samples were obtained by two main steps: formation and milling of brittle films from dispersions in water. Water was chosen as the solvent because it has good interaction with the polymer and enables obtaining brittle films, favoring milling to obtain a powder.

To obtain the materials films, $10 \%$ of PVP (w/v), the polymer mass was dissolved in water in a magnetic stirred at constant rate of $500 \mathrm{rpm}$ for 3 hours. Then the solution was cast into Petri dishes, which were placed in an oven for 48 hours at $50^{\circ} \mathrm{C}$ to dry.

The films containing $10 \%(\mathrm{w} / \mathrm{v}) \mathrm{PVP}$ and $\mathrm{ZnO}$ were obtained with varying concentrations of the nanoparticle $(0.25,0.50,0.75$ and 1\%, designated PZ025, PZ050, PZ075 and PZ100, respectively). For this, 
PVP and $\mathrm{ZnO}$ were dispersed in water in a magnetic stirred for 3 hours at a constant rate of $500 \mathrm{rpm}$. The dispersions were casting into Petri dishes, which were also placed in an oven for 48 hours at $50^{\circ} \mathrm{C}$ to dry.

The same way was used to prepare the $\mathrm{PVP} / \mathrm{ZnO}$, and the two drugs; sulfamethoxazole and trimethoprim. The aim of this part was to improve the dispersion of these drugs in the matrix system due to the reduction of the chemical interactions of the pharmaceutical structures. The proportions between sulfamethoxazole and trimethoprim were maintained according to the commercial formulation, at 5:1.

In a first step, $\mathrm{PVP}$ and $\mathrm{ZnO}$ were dispersed in water in a magnetic stirring for 1.5 hours at $500 \mathrm{rpm}$.

The sulfamethoxazole was added manually and the system was kept under stirring for another 1.5 hours. Then the dispersion was casting into Petri dishes, which were placed in an oven at $50{ }^{\circ} \mathrm{C}$ for 48 hours to dry. The dispersion containing trimethoprim was prepared with the same parameters. The samples were designated PZ025ST, PZ050ST, PZ075ST and PZ100ST, these codes were created based in the initial letter of matrix (P), initial letter of zinc oxide ( $\mathrm{Z}$ ), following the percentage number of used of $\mathrm{ZnO}$ and initial letter of each contained drug, S- sulfamethoxazole and $\mathrm{T}$ - trimethoprim.

After the complete solvent evaporation, the films were pulverized in a ball mill at $40 \mathrm{rpm}$ for 40 minutes. For the films containing sulfamethoxazole or trimethoprim, the milling also acted as a mixture step, since the drug-containing films were simultaneously added, respecting the concentrations of $\mathrm{ZnO}$.

\subsection{CHARACTERIZATION}

The samples prepared was characterized by:

$\mathrm{X}$-Ray Fluorescence Spectroscopy: Samples were analyzed in a spectrophotometry using a $4 \mathrm{~kW}$ rhodium tube, at voltage of $50 \mathrm{kV}$ and current of $50 \mathrm{~mA}$. The data were treated with the Rigaku software, RIX for Windows ${ }^{\circledR}$.

Fourier-Transform Infrared Spectroscopy: A FTIR spectrometer was used coupled to a MIRacle ${ }^{\circledR}$ attenuated total reflectance (ATR) accessory. The spectra were obtained by the average of 120 consecutive scans, with resolution of $4 \mathrm{~cm}-1$, in the interval from 4000 to $400 \mathrm{~cm}-1$.

Thermogravimetric Analysis: The thermal degradation was observed from 25 to $700^{\circ} \mathrm{C}$, with a heating rate of $10^{\circ} \mathrm{C} / \mathrm{min}$ under nitrogen atmosphere.

Differential Scanning Calorimetry: The analyzes were carried out from 25 to $300{ }^{\circ} \mathrm{C}$, at a heating rate of $10{ }^{\circ} \mathrm{C} / \mathrm{min}$ in nitrogen atmosphere at $50 \mathrm{ml} / \mathrm{min}$.

X-Ray Diffraction Analysis: the diffraction angle was $2 \theta$ registered from 2 to $50^{\circ}$ at ambient temperature with a $\mathrm{CuK} \alpha$ radiation. The data were treated with the OriginPro $8.5 \AA$ and Fityk $9.8 \circledR$ programs.

Low Field Nuclear Magnetic Resonance Spectroscopy: A low-field NMR spectrometer was used, with $18 \mathrm{~mm}$ probe for protons. The pulse sequence used to determine the proton spin-lattice relaxation time was inversion-recovery. The 90 degree pulse was automatically calibrated at $4.5 \mu \mathrm{s}, 40$ numbers of taus with 4 points each, at $28{ }^{\circ} \mathrm{C}$. The WinFit ${ }^{\circ}$ and the WinDXP® programs received with the NMR equipment were used to analyze the data.

\section{RESULTS AND DISCUSSION}

Pharmaceutical material need to have high purity, to minimize unexpected and undesirable biological effects, which can be caused by the presence of oxides or other substances that can interact and trigger organic responses. Therefore, XRF spectroscopy should be conducted before other tests are applied. The results are presented in Table 1. 
Table 1: Qualitative and quantitative analyzes of the nanoparticle and polymer by XRF

\begin{tabular}{l|l|l|l}
\hline \multicolumn{1}{r|}{ SA } & \multicolumn{1}{c}{ COMPO- } & \multicolumn{1}{c}{ RE- } \\
MPLE & SITION & (kcps) & SULTS (\%) \\
\hline $\mathrm{ZnO}$ & $\mathrm{Al}_{2} \mathrm{O} 3$ & 0.02 & 0.07 \\
& $\mathrm{SO}_{3}$ & 0.08 & 0.07 \\
& $\mathrm{Cl}$ & 0.02 & 0,04 \\
& $\mathrm{ZnO}$ & 578.9 & 99.8 \\
\hline PVP Film & $\mathrm{Fe}_{2} \mathrm{O}_{3}$ & 0.29 & 1.6 \\
& $\mathrm{NiO}$ & 0.26 & 0.5 \\
& $\mathrm{~N}$ & 1.37 & 97.9 \\
\hline
\end{tabular}

The $\mathrm{ZnO}$ solution showed a predominance of this oxide, confirming that the reagent was highly pure. Likewise, the polymer utilized, PVP, showed also be pure. In parallel to this analysis, FTIR spectroscopy was performed to corroborate the results of the composition of substances, confirming their structure. Figure 1 shows the four main bands characteristic of PVP. At low frequency, a band can be seen at $2918 \mathrm{~cm}^{-1}$, referring to the $\mathrm{C}-\mathrm{H}$ axial deformation of the cyclic chains. The bands at 1664 and $1284 \mathrm{~cm}^{-1}$ are attributed to the bifunctionality of PVP, $\mathrm{C}=\mathrm{O}$ and $\mathrm{C}-\mathrm{N}$, respectively, both in axial deformation. These bands indicate key points of the architecture of the molecular structure, especially to reaffirm the amidic nature of this polymer, essential for interaction with drugs having low solubility in water. At $1422 \mathrm{~cm}^{-1}$, the axial C-C deformation between the carbon atoms of the ring can be seen. Figure 1, also contains the FTIR spectrum of the PVP Film. In this case, the analysis was carried out for comparison of the structures before and after processing. However, the method used was not able to significantly alter the molecule's structure, since the transmittance (\%) is observed in the same band, indicating the composition was unchanged, as expected. Analyzing the $\mathrm{ZnO}$ FTIR spectrum, no organic impurities were detected, although some bands can be observed near $2000 \mathrm{~cm}^{-1}$. These can be attributed to the $\mathrm{O}-\mathrm{H}$ stretching caused by the presence of natural hydroxyl groups and humidity (Figure 1).

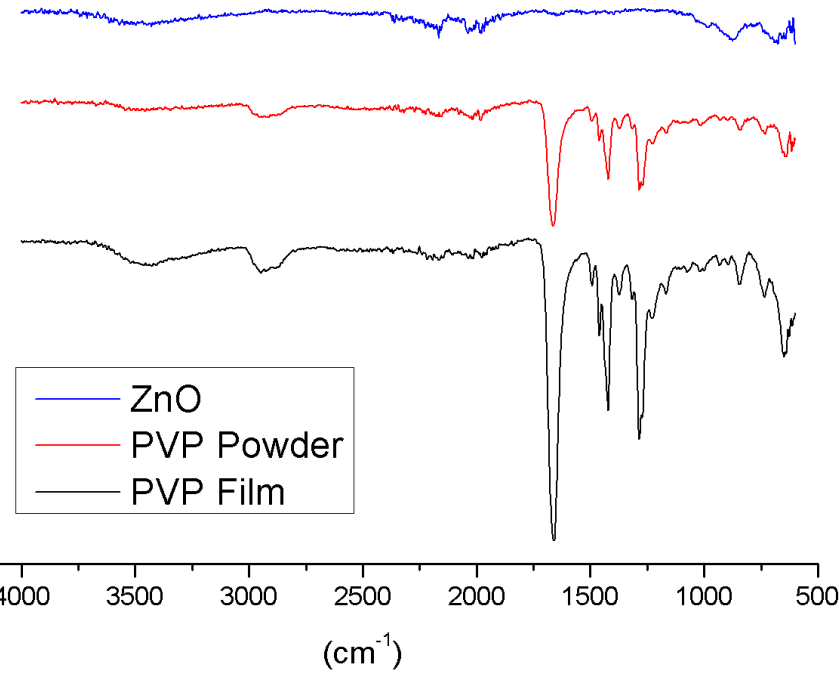

Figure 1: FTIR of PVP, PVP Film and $\mathrm{ZnO}$

Thermogravimetric analysis was used to evaluate the thermal stability of the polymer samples. Table 2 
contains the degradation temperature obtained for the commercial PVP.

Table 2: Thermal parameters of the Commercial PVP

\begin{tabular}{lclll}
\hline Sample & Moisture Content $(\boldsymbol{\%})$ & $\mathbf{T}_{\text {onset }}\left({ }^{\mathbf{0}} \mathbf{C}\right)$ & $\mathbf{T}_{\text {peak }}\left({ }^{\mathbf{o}} \mathbf{C}\right)$ & Residue (\%) \\
\hline Comercial PVP & 6 & 407 & 434 & 2
\end{tabular}

The sample underwent a small initial weight loss of approximately $6 \%(\mathrm{w} / \mathrm{w})$ at a temperature of 180 ${ }^{\circ} \mathrm{C}$. This is generally attributed to the presence of volatile components and moisture. Since this is a highly hygroscopic polymer, this type of event is expected. The main weight loss occurred in a single degradation stage, at $407.4^{\circ} \mathrm{C}$, considered to be the Tonset. This can be attributed to the rupture of important bonds for maintenance of the chain structure. The maximum degradation occurred at $433.7^{\circ} \mathrm{C}$, where $50 \%$ of the degradation process took place (T0.5). At the end of the process, $2 \%$ of the residue was observed.

All the analyses conducted with the samples following the PVP did not reveal significant variation in the degradation profile when compared with the unprocessed polymer (PVP Powder). The most relevant events are reported in Table 3. Although the values of each parameter are approximate, the results show little or very little influence of the nanoparticle in the nanocomposite. However, for total weight loss there was a gradual reduction in the percentage lost. The two drugs used were also submitted to thermogravimetric analysis, revealing the onset of thermal degradation at $232.80{ }^{\circ} \mathrm{C}$ for sulfamethoxazole and $252.81{ }^{\circ} \mathrm{C}$ for trimethoprim.

Table 3: TGA data

\begin{tabular}{llll}
\hline SAMPLE & $\begin{array}{l}\text { TONSET } \\
\left( \pm \mathbf{2}{ }^{\circ} \mathbf{C}\right)\end{array}$ & $\begin{array}{l}\text { T0,5 } \\
\left( \pm \mathbf{2}{ }^{\circ} \mathbf{C}\right)\end{array}$ & $\begin{array}{l}\text { RESIDUE } \\
(\boldsymbol{\%})\end{array}$ \\
\hline PVP Powder & 407 & 434 & 2 \\
PVP Film & 405 & 431 & 2 \\
PZ025 & 406 & 435 & 4 \\
PZ050 & 403 & 433 & 4 \\
PZ075 & 404 & 434 & 4 \\
PZ100 & 406 & 434 & 4 \\
\hline
\end{tabular}

Differential scanning calorimetry was used to measure the variation of enthalpy in function of the temperature variation $(\Delta \mathrm{T})$. Table 4 shows the glass transition values for the nanocomposites.

Table 4: Glass transition temperature of materials

\begin{tabular}{ll}
\hline SAMPLE & TG $\left( \pm 2^{\circ} \mathbf{C}\right)$ \\
\hline PZ025 & 165 \\
PZ050 & 167 \\
PZ075 & 175 \\
PZ100 & 163 \\
\hline
\end{tabular}

The glass transition temperature ( $\mathrm{Tg}$ ) could not be established from of PVP due to the level of structural disorganization. However, according to Haaf and collaborators [17], the Tg commonly reported for PVP $\mathrm{K}-30$ is about $160{ }^{\circ} \mathrm{C}$, so the values found in analyzes of the nanomaterials showed a tendency to increase the $\mathrm{Tg}$ values. The nanocomposites presented a tendency to increase the $\mathrm{Tg}$ values according to the increase in the $\mathrm{ZnO}$ ratio up to $0.75 \%$ (increase of $15^{\circ} \mathrm{C}$ in the value of $\mathrm{Tg}$ ) and showed a significant decrease for the $1 \%$ of $\mathrm{ZnO}$ incorporated, suggesting that there was good dispersion up to $0.75 \%$ of $\mathrm{ZnO}$ due to the intermolecu- 
lar interactions, promoting changes in the molecular mobility.

Figure 2 presents the XRD results, showing peaks in $30^{\circ}$ to $50^{\circ}$ related to $\mathrm{ZnO}$. These peaks are increased in the nanocomposites according to the increase of nanoparticle ratio. From these diffractograms was obtained the crystallinity degree (Xc) for the samples. PVP presents only an amorphous halo. Its nanocomposites with $\mathrm{ZnO}$ (Figure 2) and the systems containing the drugs (Figure 3) presented same crystallinity degree (Tables 5 and 6), demonstrating that the interaction of the components was not sufficient to promote changes in the crystallinity degree.

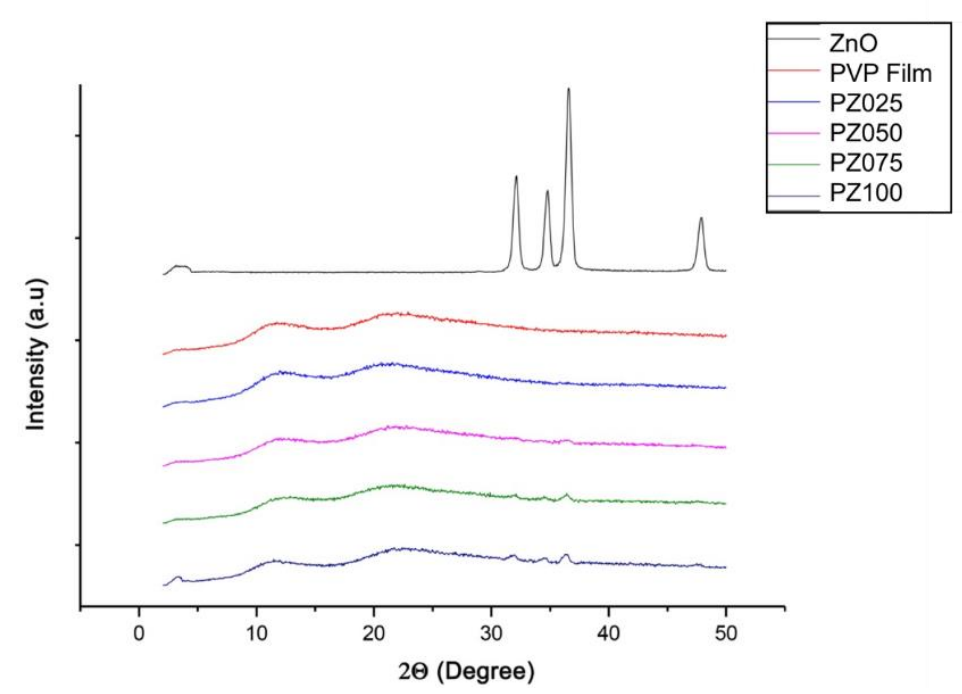

Figure 2: X-rays curves of samples before drugs incorporation

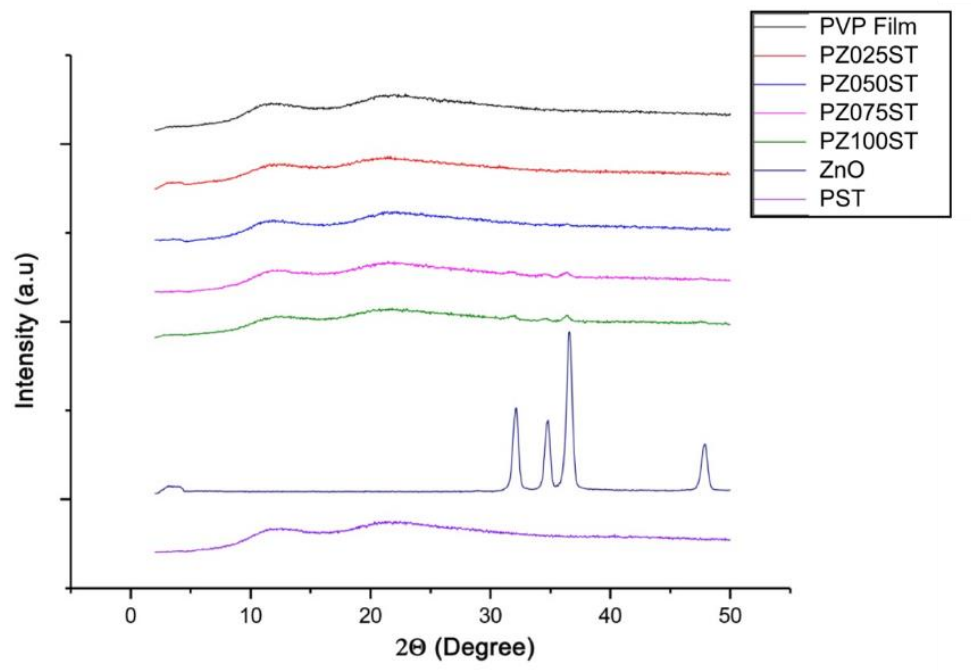

Figure 3: X-rays curves of samples containing Sulfametoxazol and Trimetoprima 
Table 5: Crystallinity degree (\%) of the samples before drugs incorporation

\begin{tabular}{lc}
\hline \multicolumn{1}{c}{ SAMPLE } & DEGREE OF CRYSTALLINITY (\%) \\
\hline ZnO & 85 \\
PVP Film & 22 \\
PZ025 & 19 \\
PZ050 & 22 \\
PZ075 & 22 \\
PZ100 & 22 \\
\hline
\end{tabular}

Table 6: Crystallinity degree (\%) of the samples containing drugs

\begin{tabular}{lc}
\hline SAMPLE & DEGREE OF CRYSTALLINITY (\%) \\
\hline ZnO & 85 \\
PVP Film & 22 \\
PVP ST & 22 \\
PZ025ST & 21 \\
PZ050ST & 23 \\
PZ075ST & 23 \\
PZ100ST & 23 \\
\hline
\end{tabular}

The molecular dynamical behavior of the PVP and its nanomaterials were evaluated by NMR relaxometry, through the proton spin-lattice relaxation time, which is a parameter sensitive the small changes in the intermolecular interaction and nanoparticle dispersion [6], [18], [19]. Firstly, the commercial PVP was analyzed and relaxation behavior was used to compare with the samples after $\mathrm{ZnO}$ incorporation, to observe the changes in the molecular dynamics, due to intermolecular interaction and $\mathrm{ZnO}$ dispersion, since the nanoparticles has good dispersion and distribution in the PVP matrix. 


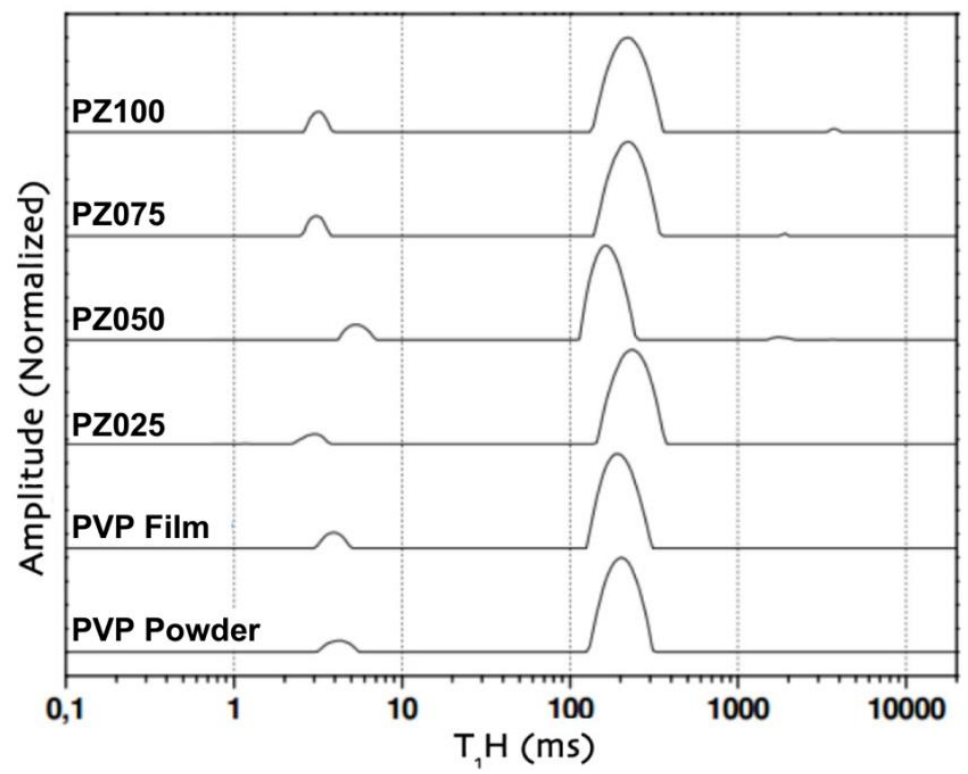

Figure 4: Domain distribution of the relaxation times of the samples

Figure 4 shows the distribution curves of the relaxation time for PVP and the nanocomposites. All domains relaxation curves contain a small domain with lower amplitude, below $10 \mathrm{~ms}$, referring to the presence of moisture due to the hydrophilic samples nature. The distribution of relaxation times curves for samples containing nanoparticles presented a similar pattern. It was noted that the addition of $\mathrm{ZnO}$ caused an alteration of the molecular dynamics of the PVP matrix, leading to changes in the values of relaxation times (Table 7) when compared to the pure polymer sample.

Table 7: Relaxation time $\mathrm{T}_{1}$ determined from 1 exponential

\begin{tabular}{lc}
\hline \multicolumn{1}{c}{ SAMPLE } & $\mathbf{T}_{\mathbf{1}} \mathbf{H}(\mathbf{m s})$ \\
\hline PVP Powder & 179 \\
PVP Film & 170 \\
PZ025 & 214 \\
PZ050 & 144 \\
PZ075 & 196 \\
PZ100 & 199 \\
\hline
\end{tabular}

In PZ100 and PZ025 systems, a very subtle enlargement of the domains was observed in comparison with the polymer and also an increase in the relaxation time values, indicating the formation of a new material, containing good dispersion and distribution of the $\mathrm{ZnO}$ in polymer matrix, making the new hybrid material rigid. For PZ075 system, there was a small decrease in the values of relaxation times, although the base of the domains had similar width as the PVP Film, suggesting that the dispersion of the nanoparticles caused an increase in the system's molecular mobility, but without achieving a better distribution. However, sample PZ050 presented a greater shift to shorter relaxation time value, along with narrowing of the domain relaxation curve. This is an indication that the nanomaterial presented higher molecular mobility comparing to PVP Film, and the dispersion and distribution of $\mathrm{ZnO}$ particles more homogeneous, generating a new material with good characteristics comparing to other composites and PVP. These characteristics come from the nanostructured organization of the particles in the matrix system. Thus, these results may suggest that PZ050 system could be more adequate than the others when applied to fast drug release systems because present a low relaxation time, in other words this system needs less energy to release the drug and in the same way the PZ025 is adequate to drug slow release systems. In all characterizations showed in this work those samples present similar characteristics, though with opposite behavior of molecular mobility. The molecular mobility 
is an important parameter to control the way and the velocity of drug release by erosion of the matrix and by drug diffusion.

\section{CONCLUSION}

The method used to obtain the nanomaterials do not change the crystallinity degree or thermal properties. This is a good aspect because allows keep the traditional compressed tablet drugs preparation. The addition of distinct concentrations of zinc oxide nanoparticles in PVP matrix formed hybrid materials with good dispersion and distribution in the PVP matrix as relaxation times shows. The results suggest that PZ025 and PZ050 systems are adequate to applied to slow and fast drug release systems, respectively.

\section{ACKNOWLEDGEMENT}

The authors are grateful to Brazilian agencies CAPES, CNPq and FAPERJ for the financial support of this research and for the scholarship of the student.

\section{BIBLIOGRAPHY}

[1] PEZZINI, B. R., SILVA, M. A. S., FERRAZ, H. G. "Formas farmacêuticas sólidas orais de liberação prolongada: sistemas monolíticos e multiparticulados”, Rev. Bras. Ciências Farm., v. 43, n. 4, 2007.

[2] DASH, S., MURTHY, P. N., NATH, L., et al., "Kinetic modeling on drug release from controlled drug delivery systems", Acta Pol. Pharm., v. 67, n. 3, pp. 217-23, 2010.

[3] LOPES, C. M., LOBO, J. M. S., COSTA, P. "Formas farmacêuticas de liberação modificada: polímeros hidrifílicos", Rev. Bras. Ciências Farm., v. 41, n. 2, pp. 143-154, 2005.

[4] SOPPIMATH, K. S., AMINABHAVI, T. M., KULKARNI, A. R., "Biodegradable polymeric nanoparticles as drug delivery devices”, J. Control. Release, v. 70, n. 1-2, pp. 1-20, Jan. 2001.

[5] DORNELAS, C. B., RESENDE, D.K., ROCHA, H.V.A., et al., "Avaliação de derivados poliméricos intercalados em montmorilonita organofílica na preparação de novos materiais de uso farmacêutico", Polímeros, v. 18, n. 3, pp. 222-229, Sep. 2008.

[6] ALMEIDA, A.S.,TAVARES, M.I.B., SILVA, E.O., et al., "Development of hybrid nanocomposites based on PLLA and low-field NMR characterization”, Polym. Test., v. 31, n. 2, pp. 267-275, Apr. 2012.

[7] MANADAS, R., PINA, M. E., VEIGA, F. “A dissolução in vitro na previsão da absorção oral de fármacos em formas farmacêuticas de liberação modificada”, Rev. Bras. Ciência do Solo, v. 38, n. 4, 2002.

[8] ANDREETTA, H. A. "Fármacos de Acción Prolongada: Mecanismos de Liberación. Usos de distintos modelos", Acta Farm. Bonaer., v. 22, n. 4, pp. 355-363, 2003.

[9] CUNHA, A.P.C.B., TAVARES, M. I. B., SILVA, E.O., "Application of NMR Relaxometry to Study Nanostructured Poly(vinyl alcohol)/MMT/Cephalexin Materials for Use in Drug Delivery Systems”, Mater. Sci. Appl., v. 7, n. 7, pp. 380-387, 2016.

[10] SEBASTIÃO, P. J., MONTEIRO, M. S. S. B., BRITO, L. M., et al., "Conventional and Fast Field Cycling Relaxometry Study of the Molecular Dynamics in Polymer Nanocomposites for Use as Drug Delivery Systems", J. Nanosci. Nanotechnol., v. 16, n. 7, pp. 7539-7545, Jul. 2016.

[11] COELHO, P. "Desenvolvimento de formulações de libertação modificada de ranitidina", Tese de D.Sc., Universidade do Porto, Portugal, 2007.

[12] VILlAnOVA, J. C. O., ORÉFICE, R. L., CUNHA, A. S. "Aplicações Farmacêuticas de Polímeros", Polímeros Ciência e Tecnol., v. 20, n. 1, pp. 51-64, 2010.

[13] DORNELAS, C. B., RESENDE, D. K., GOMES, A. S. "Preparação e Avaliação Reacional de Nanocompósitos de PVP K-30 - Montmorilonita ( Natural e Organicamente Modificada ) por Difração de Raios X”, Polímeros Ciência e Tecnol., v. 18, n. 2, pp. 187-192, 2008.

[14] SCHAFFAZICK, S. R., GUTERRES, S. S., FREITAS, L.L. "Caracterização e estabilidade físicoquímica de sistemas poliméricos nanoparticulados para administração de fármacos”, Quim. Nova, v. 26, n. 5, pp. 726-737, 2003.

[15] MALI,R.R., GOEL,V., GUPTA, S., "Novel Study in Sustained Release Drug Delivery System : A Review”, Int. J. Pharm. Med. Res., v. 3, n. 2, pp. 204-215, 2015.

[16] TIBBITT, M. W., DAHLMAN, J. E., LANGER, R., "Emerging Frontiers in Drug Delivery", J. Am. Chem. Soc., v. 138, n. 3, pp. 704-717, Jan. 2016. 
[17] HAAF, F., SANNER, A., STRAUB, F., "Polymers of N-vinylpyrrolidone: Synthesis, characterization and uses", Polymer Journal, v. 17, n. 1. pp. 143-152, 1985.

[18] MENDES, L. C., SILVA, D. F., ARAUJO, L. J. F., et al., "Zirconium phosphate organically intercalated/exfoliated with long chain amine", J. Therm. Anal. Calorim., Aug. 2014.

[19] MONTEIRO, M. S. S. B., LUNZ, J., SEBASTIÃO, P. J., et al., "Evaluation of Nevirapine Release Kinetics from Polycaprolactone Hybrids”, Mater. Sci. Appl., v. 7, pp. 680-701, 2016. 